\title{
Use of tensor fascia lata flap for reconstruction of the defect created following inguinal block dissection in a case of carcinoma penis: a case report and brief review of literature
}

\author{
Amitabh Jena', Banoth Manilal', Sriharsha Haranadh' ${ }^{1}$, Rashmi Patnayak $^{2}$ \\ ${ }^{1}$ Department of Surgical Oncology, Sri Venkateswara Institute of Medical Sciences, Tirupati 517507, Andhra Pradesh, India. \\ ${ }^{2}$ Department of Pathology, Sri Venkateswara Institute of Medical Sciences, Tirupati 517507, Andhra Pradesh, India.
}

Address for correspondence: Prof. Amitabh Jena, Department of Surgical Oncology, Sri Venkateswara Institute of Medical Sciences, Tirupati 517507, Andhra Pradesh, India. E-mail: dramitabh2004@yahoo.co.in

\begin{abstract}
Tensor fascia lata (TFL) flap is a versatile myofasciocutaneous flap. It has varied usages as both free and pedicled flap. As a pedicled flap, it is a good option for reconstructing soft tissue defects after tumor ablation. The TFL perforator flap is a good alternative for anterolateral thigh (ALT) flap. The advantages of TFL flap are that dissection can be made through the same incision, without impairment of other donor sites. The reconstructive plan remains same as that of ALT flap. TFL flap offers a good volume of skin and can be made thin removing variable portions of muscle. The present case is a 63-year-old patient with a carcinoma penis who underwent left ilioinguinal block dissection resulting in a defect of $8 \mathrm{~cm} \times 8 \mathrm{~cm}$ in the left inguinal region. TFL flap was raised with U-shaped incision and used for closure of the defect with good result.
\end{abstract}

Key words:

Groin reconstruction, myofasciocutaneous flap, tensor fascia lata flap

\section{INTRODUCTION}

Tensor fascia lata (TFL) flap is a myofasciocutaneous flap. In 1934, Wangensteen, ${ }^{[1]}$ first described it for abdominal wall reconstruction. It is a versatile flap with many uses in reconstructive plastic surgery like in management of pressure sores, facial reanimation and as a free flap in head and neck reconstruction. ${ }^{[2]}$ As a pedicled flap, its strong fascial layer has the advantage of reaching the lower abdomen and the groin. Thus, it is a good option for reconstructing soft tissue defects after tumor ablation.

\begin{tabular}{|l|l|}
\hline \multicolumn{2}{|c|}{ Access this article online } \\
\hline Quick Response Code: & Website: \\
\hline & www.parjournal.net \\
\cline { 2 - 2 } & \\
\hline & \\
\hline
\end{tabular}

The problem with TFL is distal necrosis in both pedicled and free form. The flap's safe dimensions and adequacy to minimize distal tip necrosis for a sound abdominal wall reconstruction remains controversial. ${ }^{[2-5]}$

The aim of the present case report was to share our experience and clinical observations with TFL flap used in the reconstruction of a challenging defect following inguinal block dissection in a case of the carcinoma penis.

\section{CASE REPORT}

A 63-year-old male patient who was a diagnosed case of the carcinoma penis with bilateral inguinal lymphadenopathy underwent partial penectomy 6 months back. Left inguinal lymph node dissection was also planned after 2 weeks, and he was discharged on antibiotic cover. The patient defaulted for 3 months and presented with a fungating left inguinal lymph nodal mass. He was treated with external radiotherapy with 60 Gy in 30 fractions over 6 weeks. 
Later, the patient presented with a residual mass over left inguinal region. There was a hard swelling of $4 \mathrm{~cm} \times 3 \mathrm{~cm}$ with restricted mobility in left inguinal region [Figure 1]. Also, multiple small lymph nodes were palpable on the right side, the largest measuring $1 \mathrm{~cm} \times 1 \mathrm{~cm}$.

Magnetic resonance image of the left inguinal region showed enlarged necrotic lymph node, anterior to femoral vessels in the subcutaneous plane. There was a loss of fat planes with left femoral vein. Left femoral artery and right inguinal region were normal. Fine needle aspiration cytology was done from bilateral inguinal lymph nodes. The left inguinal lymph node showed squamous cell carcinomatous deposit. The right inguinal lymph nodes were reactive in nature without any tumor deposit. Chest X-ray was reported as normal. Routine hematological and biochemical investigations like complete hemogram, serum urea and creatine were within normal limit. Viral markers like human retroviral antigen, hepatitis $\mathrm{B}$ and $\mathrm{C}$ were also negative.

He underwent left ilioinguinal block dissection. Perioperatively, there were necrotic lymph nodes of $4 \mathrm{~cm} \times 4 \mathrm{~cm}$ in size, abutting the femoral vein. Multiple lymph nodes were present in iliac region, largest measuring $3 \mathrm{~cm} \times 1 \mathrm{~cm}$. The Cloquet lymph node was also present. Three $\mathrm{cm}$ skin margin was taken beyond the indurated area thereby creating a defect of $8 \mathrm{~cm} \times 8 \mathrm{~cm}$ in the left inguinal region [Figure 2].

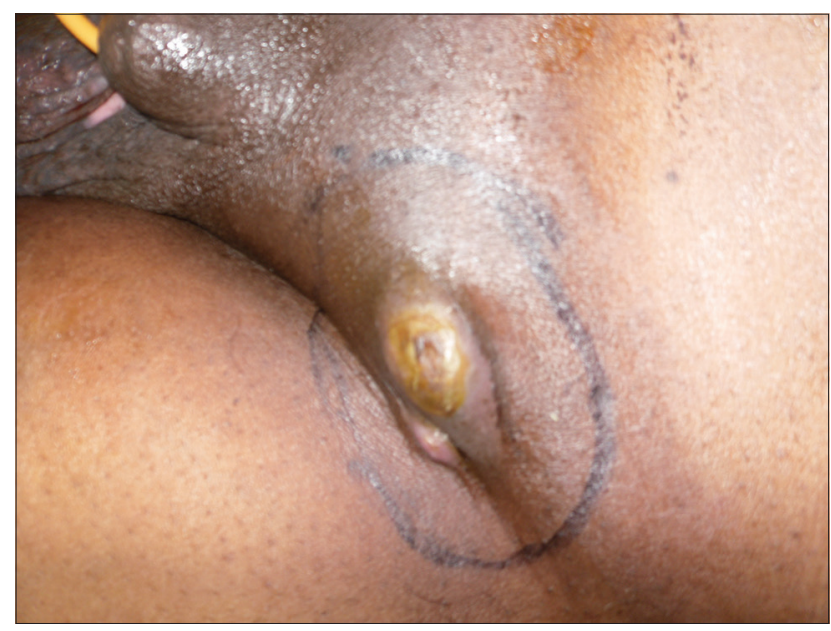

Figure 1: Residual left inguinal lymph nodal mass (postradiotherapy)

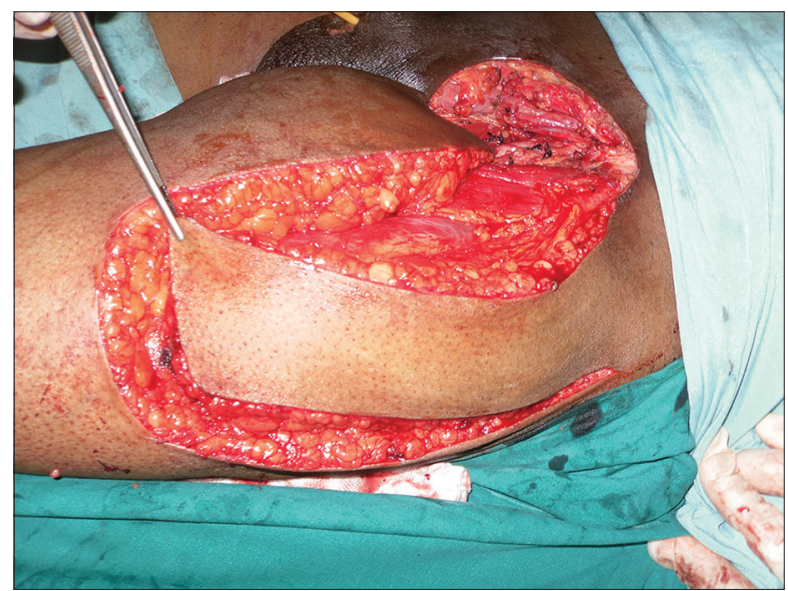

Figure 3: Flap after dissecting all around
It was decided to cover the defect with TFL pedicle flap. We followed the same technique of harvesting of TFL as described by various authors. ${ }^{[2,4]}$ The donor flap outlining was done with U-shaped incision on the thigh. The elevation was carried out in a subfascial plane from distal to proximal. The lateral circumflex femoral artery was then easily identified high up as it passes between the rectus femoris and the vastus lateralis, where it gives the transverse branch, which pierces the TFL muscle accompanied by venae comitantes. Then dissection was performed to sufficiently mobilize the flap for proper defect coverage [Figure 3]. The medial end of the incision was joined to the lateral aspect of the inguinal defect. The free end of the flap was then rotated upward and medially [Figure 4] and sutured to the defect created by the inguinal dissection. Donor site could be approximated without any tension [Figure 5]. Drain was placed, and wound was closed in layers.

Postoperative period was uneventful. Flap was healthy on the seventh postoperative day, and the patient was discharged. He was advised to undergo regular follow-up. Suture and skin stapler was removed on the 14th day. There was no necrosis or dehiscence, and the cosmesis was acceptable.

Other options for alternative flaps in this case would have been perforator based anterolateral thigh (ALT)

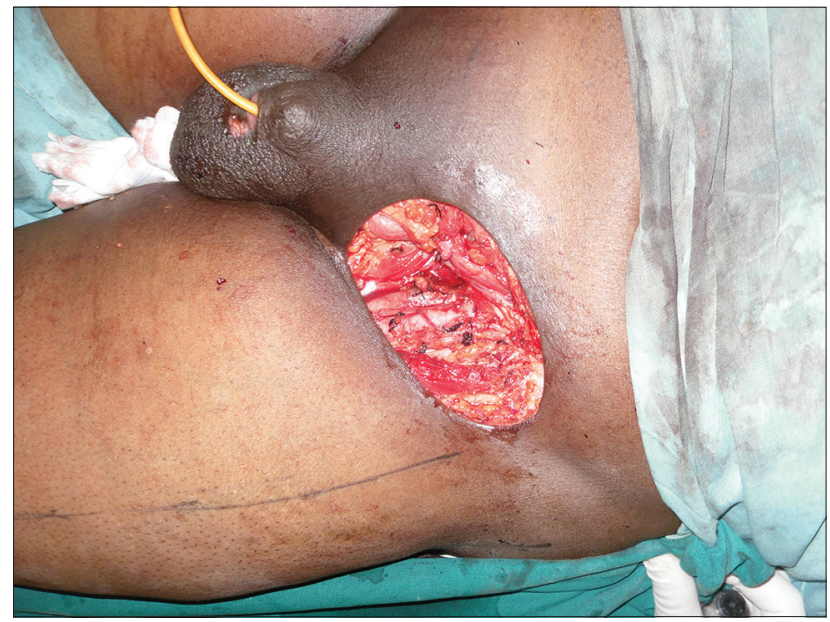

Figure 2: Defect created after inguinal block dissection

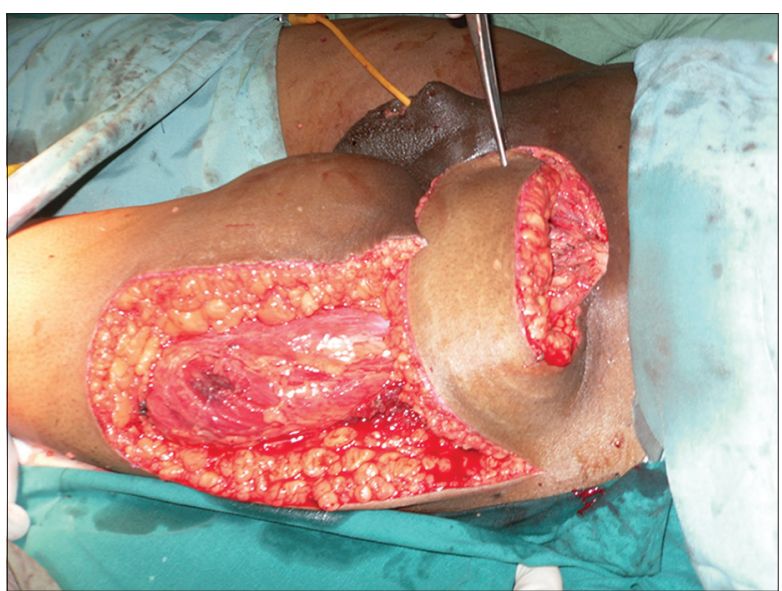

Figure 4: The free end of the flap was rotated upward and medially to the defect 


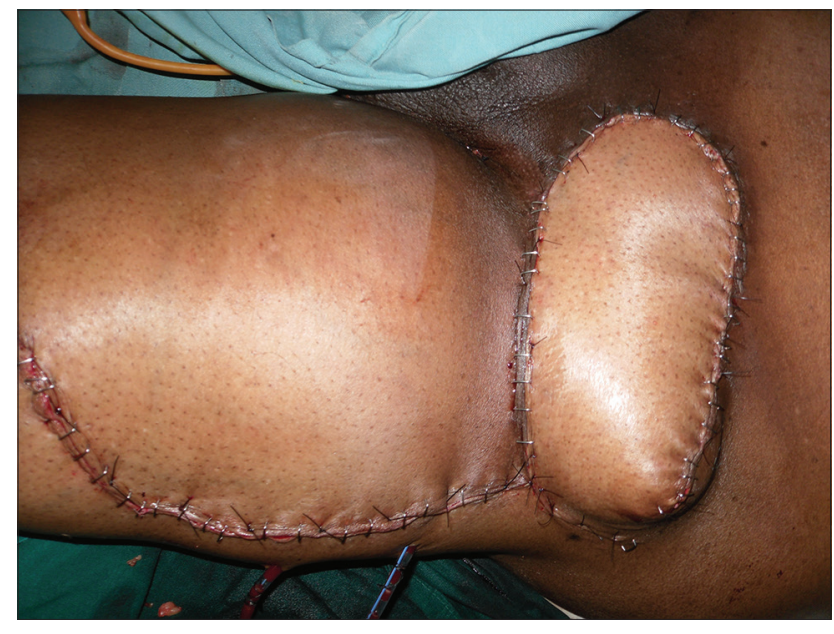

Figure 5: Primary and donor site approximated without tension

flap. We preferred TFL particularly in this case. The dissection could be done through the incision joining inguinal block dissection. The defect created was closed without any tension and with acceptable cosmetic result. A simple upper and medial or rotation of the flap helped us to approximate the donor site and close it primarily [Figures 4 and 5].

\section{DISCUSSION}

The soft tissue tumors in the groin area need adequate resection to achieve optimal local treatment and to minimize recurrence. The resultant wounds are slow healing in nature and are frequently exposed to vital structures like femoral vessels, thereby increasing the complication rate..$^{\mid 6-9]}$

Several flaps have been described to cover established groin defects, namely, inferiorly based rectus abdominis muscle or myocutaneous flap, rectus femoris, sartorius with abdominal skin flap, internal oblique muscle flap, and vastus lateralis flaps. ${ }^{[2-5]}$ These flaps have their advantages and disadvantages. Abdominal weakness, bulging or hernia, and knee weakness are some of the complications associated with these flaps. ${ }^{[2]}$

ALT flap is considered as the gold standard in head and neck reconstructions as free flaps and as pedicle flaps in abdominal wall reconstruction. ${ }^{[10,11]}$ The advantage of this flap is that it offers a good volume of pliable tissues and a pedicle characterized by good caliber and adequate length. Its main disadvantage is its anatomical variability in number and location of perforator vessels. The absence of perforators is rare, but can occur. In these instances, TFL perforator flap can be a good alternative to ALT flap. ${ }^{[10,11]}$

TFL flap is a myocutaneous flap that can either be used as a free flap or as a pedicled flap depending on the site. It can be used as a free flap in the head and neck reconstruction, and as a pedicled flap in abdominal wall reconstructions. The advantage of TFL flap is that it allows the usage of the same donor site thereby avoiding another surgical incision. Its anatomy is more constant. Perforators are almost always present, and their pedicles are of sufficient length (average of $8 \mathrm{~cm}$ ). As a perforator flap, a thinner and more pliable flap can be obtained, removing a variable portion of muscular tissue and leaving only a cuff around the pedicle. Therefore, it can be used for almost the same indications of ALT flap..$^{[2-5]}$

The published reports of TFL flap in groin reconstruction following inguinal node dissection have enumerated partial flap necrosis, distal tip necrosis, flap infection and lymphedema as various complications..$^{[2,3,5]}$

In our case, we found TFL perforator flap to be the best choice because it allowed maintaining the same reconstructive plan made with the ALT flap.

In conclusion, the TFL flap is a reliable flap for inguinal area defect reconstruction, without any donor site morbidity. Because we could close the defect primarily without skin graft, it was cosmetically very well accepted by the patient.

\section{REFERENCES}

I. Wangensteen $\mathrm{OH}$. Repair of recurrent and difficult hernias and other large defects of the abdominal wall employing the iliotibial tract of fascia lata as a pedicled flap. Surg Gynecol Obstet 1934;59:766-80.

2. Murthy V, Gopinath KS. Reconstruction of groin defects following radical inguinal lymphadenectomy: an evidence based review. Indian J Surg Oncol 2012;3:130-8.

3. Agarwal AK, Gupta S, Bhattacharya N, Guha G, Agarwal A. Tensor fascia lata flap reconstruction in groin malignancy. Singapore Med J 2009;50:78I-4.

4. Akhtar MS, Khurram MF, Khan AH. Versatility of pedicled tensor fascia lata flap: a useful and reliable technique for reconstruction of different anatomical districts. Plast Surg Int 20I4;20I4:846082.

5. Nirmal TJ, Gupta AK, Kumar S, Devasia A, Chacko N, Kekre NS. Tensor fascia lata flap reconstruction following groin dissection: is it worthwhile? World J Urol 201 I;29:555-9.

6. Rifaat MA, Abdel Gawad WS. The use of tensor fascia lata pedicled flap in reconstructing full thickness abdominal wall defects and groin defects following tumor ablation. J Egypt Natl Canc Inst 2005; I 7: 139-48.

7. Hubmer MG, Justich I, Haas FM, Koch H, Parvizi D, Feigl G, Prandl E. Clinical experience with a tensor fasciae latae perforator flap based on septocutaneous perforators. J Plast Reconstr Aesthet Surg 201 I;64:782-9.

8. Mack LA, Temple WJ, DeHaas WG, Schachar N, Morris DG, Kurien E. Groin soft tissue tumors - a challenge for local control and reconstruction: a prospective cohort analysis. J Surg Oncol 2004;86: I47-5I.

9. Payne WG, Walusimbi MS, Blue ML, Mosiello G, Wright TE, Robson MC. Radiated groin wounds: pitfalls in reconstruction. Am Surg 2003;69:994-7.

10. Contedini F, Negosanti L, Pinto V, Tavaniello B, Fabbri E, Sgarzani R, Tassone D, Cipriani R. Tensor fascia latae perforator flap: an alternative reconstructive choice for anterolateral thigh flap when no sizable skin perforator is available. Indian J Plast Surg 2013;46:55-8.

II. Lannon DA, Ross GL, Addison PD, Novak CB, Lipa JE, Neligan PC. Versatility of the proximally pedicled anterolateral thigh flap and its use in complex abdominal and pelvic reconstruction. Plast Reconstr Surg 20 I ; 127:677-88.

How to cite this article: Jena A, Manilal B, Haranadh S, Patnayak R. Use of tensor fascia lata flap for reconstruction of the defect created following inguinal block dissection in a case of carcinoma penis: a case report and brief review of literature. Plast Aesthet Res 2015;2:144-6.

Source of Support: Nil, Conflict of Interest: None declared.

Received: 25-11-2014; Accepted: 13-02-2015 